\title{
100 Cases of Clinical and Etiological Aspects of Cardiac Insufficiency in N'Djamena, Chad
}

\author{
Natingar Madjirangar ${ }^{1,2}$, Adam Ahamat Ali2,3*, Bekoutou Amngar ${ }^{4}$, Jean Philippe Lesbre ${ }^{4}$ \\ ${ }^{1}$ National General Reference Hospital of N’Djamena, N'Djamena, Chad \\ ${ }^{2}$ Faculty of Human Health Sciences of N'Djamena, N'Djamena, Chad \\ ${ }^{3}$ Renaissance Hospital of N'Djamena, N'Djamena, Chad \\ ${ }^{4}$ The Good Samaritan Hospital of N'Djamena, N’Djamena, Chad \\ Email: madjirangar@yahoo.fr, *aliadamahmat@hotmail.com, amngarbekoutou@yahoo.fr, jphlesbre@orange.fr
}

How to cite this paper: Madjirangar, N., Ali, A.A., Amngar, B. and Lesbre, J.P. (2019) 100 Cases of Clinical and Etiological Aspects of Cardiac Insufficiency in N'Djamena, Chad. World Journal of Cardiovascular Diseases, 9, 612-619.

https://doi.org/10.4236/wjcd.2019.98053

Received: June 13, 2019

Accepted: August 24, 2019

Published: August 27, 2019

Copyright (c) 2019 by author(s) and Scientific Research Publishing Inc. This work is licensed under the Creative Commons Attribution International License (CC BY 4.0).

http://creativecommons.org/licenses/by/4.0/

\section{Open Access}

\begin{abstract}
Introduction: Cardiac Insufficiency is progressively taking over as the leading cause of morbidity and mortality in the world and a major public health problem in Chad. Our study was to contribute and provide a deeper understanding of the clinical and etiological aspects concerning the etiology and management of Cardiac Insufficiency in N'Djamena, Chad. Due to having no published data to distinctly understand this pathology in this part of the world, we represent here a summary of available data which could be used to describe the clinical and etiological aspects of Cardiac Insufficiency and to help in changing practices for an optimal management as a baseline for comparison in future studies. Patients and Methods: This was a prospective, descriptive study conducted from November 30th 2011 to May 30th 2013 at the Good Samaritan Hospital of N'Djamena. Results: 100 hospitalized patients were included consecutively. The sex ratio was 1.08 with an average age of $40.21 \pm 21.30$ years. The main cardiovascular risk factors were high blood pressure (15\%), obesity (12\%) and diabetes (11\%). Clinically, exertional dyspnea was found in $95 \%$ of cases, and signs of congestive heart failure in $61 \%$ of cases. The etiologies were $50 \%$ of Rheumatic valvulopathy, $22 \%$ of Dilated cardiomyopathy, $13 \%$ of Hypertensive cardiomyopathy and $12 \%$ of Congenital heart disease. Conclusion: The most common etiologies were Rheumatic valvulopathy, Congenital heart disease, Dilated cardiomyopathy and Hypertensive cardiomyopathy.
\end{abstract}

\section{Keywords}

Cardiac Insufficiency, Etiology, Echocardiography, N’Djamena, Chad 


\section{Introduction}

Cardiac Insufficiency (CI) is a common pathology worldwide. It is a clinical syndrome characterized by chronic symptoms (e.g. dyspnea, fatigue) that may be accompanied by physical signs (e.g. crepitations, peripheral edema) caused by a structural and/or functional cardiac abnormality, which causes a decrease in cardiac output [1]. CI is a major global public health problem affecting 40 million people worldwide in 2015 [2]. CI represents one of the leading causes of hospitalization, morbidity and mortality, especially among the elderly [3]. In western countries, the incidence and prevalence of $\mathrm{CI}$ are increasing due to the aging of the population [1]. The prevalence was estimated at $1 \%-2 \%$ of the adult population [1] [4], while the incidence rate is generally estimated at 2 to 5 per 1000 people annually [5] [6]. In Africa, CI is one of the main circumstances in the discovery of cardiovascular disease with an incidence of 1 to 3 per 1000 people annually and a prevalence of 3 to 20 per 1000 people annually, often at an advanced stage [7]. According to World Health Organization estimates, cardiovascular disease is the second leading cause of death in Africa. In 2015, nearly 1.2 million people died of heart disease in Africa, which is more than Malaria and Tuberculosis combined [8]. Despite improvements observed in the survival of patients with CI in recent years, overall prognosis remains poor [3] [9] with $50 \%$ survival estimates at 5 years after initial CI diagnosis [10] [11]. However, in Chad, we do not have data on this pathology. The objective of this work was to identify the etiology of CI in Chad.

\section{Patients and Methods}

This was a study conducted from November 30th 2011 to May 30th 2013 at the Good Samaritan Hospital of N'Djamena. We consecutively included all the patients that were hospitalized for CI during this study period. Patients who refused to give their consent were excluded. There were no specific selection criteria. The variable studies were clinical (history, cardiovascular risk factors, functional signs, physical signs), biological (HIV serology, blood count, thyroid hormone, serum creatinine, blood urea, electrolyte panel, blood glucose) and echocardiographic (dilation, hypertrophy and left ventricular ejection fraction, valvular abnormalities, pulmonary arterial pressures, and pericardial abnormalities).

The system used was the HP 1000 ET 5500 model. The following parameters were specified:

- Dilation of the Left Ventricle

- Left Ventricular Hypertrophy

- Systolic Dysfunction

- Valvulopathy

- Congenital Heart Disease

\section{Statistical analysis}

In this study, a descriptive statistical analysis was applied using Microsoft Excel, quantitative variables were presented by their mean and standard deviation 
and qualitative variables were by percentages.

\section{Declaration of ethics}

The study was conducted after an agreement of the Ethics Committee of the Faculty of Medicine of N'Djamena and with the consent of patients.

\section{Results}

100 patients were included. Table 1 summarizes the characteristics of this population. The sex ratio was 1.08 (52 men) with an average age of $40.21 \pm 21.30$ years with a predominance of patients aged 20 to 29 years and those with an age greater than or equal to 50 years of age. The main cardiovascular risk factors were high blood pressure (15\%), obesity (12\%) and diabetes (11\%). Other risk factors identified were dyslipidemia (02\%), alcohol (10\%), smoking (04\%), and renal dysfunction (09\%).

Clinically (Table 2), exertional dyspnea was observed in $95 \%$ of cases, and the signs of global CI were $61 \%$ of cases.

Table 1. Characteristics of the population.

\begin{tabular}{ccc}
\hline Settings & Number $(\mathrm{N})$ & Percentage (\%) \\
\hline Sex: & 48 & 48 \\
Women & 52 & 52 \\
Man & & \\
Age (year): & $40.21 \pm 21.30$ & 24 \\
Means & 24 & 27 \\
$<20$ & 27 & 10 \\
$20-29$ & 10 & 12 \\
$30-39$ & 12 & 27 \\
$40-49$ & 27 & \\
$\geq 50$ & & 12 \\
Risk factors: & 12 & 11 \\
Obesity & 11 & 02 \\
Diabetes & 02 & 10 \\
Dyslipidemia & 10 & 04 \\
Alcohol & 04 & 15 \\
Smoking & 15 & 09 \\
Hypertension & 09 & \\
Renal Dysfunction & &
\end{tabular}

Table 2. Clinical manifestations.

\begin{tabular}{ccc}
\hline & Number $(\mathrm{N})$ & Percentage $(\%)$ \\
\hline Functional signs: & & \\
Dyspnea & 95 & 95 \\
Orthopnea & 15 & 15 \\
Hemoptysis & 18 & 53 \\
Palpitations & 53 & 15 \\
Hepatalgia & 15 & \\
Physical signs: & & 29 \\
Left CI signs & 29 & 10 \\
Right CI signs & 10 & 61 \\
Signs of global CI & 61 &
\end{tabular}


Regarding the etiologies of CI (Table 3), Rheumatic heart valve disease was found in $48 \%$ of cases including (11\%) Mitral stenosis, (13\%) Mitral insufficiency, (06\%) Mitral diseases, (3\%) Aortic stenosis, (2\%) Aortic insufficiency, (4\%) Aortic disease, and (9\%) Polyvalvulopathy. The dysfunctions of the prosthetic valves were found in (2\%) of cases all in the mitral position, which were mechanical and bioprosthetic. 22\% of Dilated cardiomyopathies (DCM) including (8\%) primary DCM, (4\%) Ischemic DCM, (5\%) Peripartum DCM, (3\%) Ethyl DCM, (1\%) Cardiothorosis DCM and (1\%) Rhythmic DCM. Hypertensive cardiomyopathies were found in $13 \%$ of cases, $12 \%$ congenital heart disease, $2 \%$ pericardial disease, and $1 \%$ idiopathic pulmonary arterial hypertension (IPAH). Table 3 presents the etiologies of CI by age group (Figure 1).

\section{Discussion}

CI is a global public health problem. In Chad, we do not have epidemiological data on this pathology. In this study the mean age was $40.21 \pm 21.30$ years and more than half of our patients were under 50 years of age. Several authors in Sub-Saharan Africa have found similar results [12] [13] [14]. In the West, according to the Framingham Cohort study, the average age was 70 [15]. This difference in the average age with the West, is related to the lack of medical coverage and the reduced life expectancy at home. The leading cardiovascular risk

Table 3. Etiologies of CI.

\begin{tabular}{|c|c|c|c|}
\hline \multicolumn{2}{|r|}{ Etiology } & \multirow{2}{*}{$\begin{array}{c}\text { Number }(\mathrm{N}) \\
11\end{array}$} & \multirow{2}{*}{$\begin{array}{c}\text { Percentage }(\%) \\
11\end{array}$} \\
\hline & Mitral stenosis & & \\
\hline & Mitral insufficiency & 13 & 13 \\
\hline & Mitral disease & 06 & 06 \\
\hline \multirow[t]{4}{*}{ Rheumatic Valvulopathy } & Aortic stenosis & 03 & 03 \\
\hline & Aortic insufficiency & 02 & 02 \\
\hline & Aortic disease & 04 & 04 \\
\hline & Polyvalvulopathy & 09 & 09 \\
\hline \multicolumn{2}{|c|}{ Prosthesis Dysfunction } & 02 & 02 \\
\hline \multirow{4}{*}{ Congenital Heart Disease } & Inter auricular communication & 01 & 01 \\
\hline & Inter ventricular communication & 04 & 04 \\
\hline & Atrio-ventricular canal & 02 & 02 \\
\hline & Complex heart disease & 05 & 05 \\
\hline \multirow{6}{*}{ Dilated Cardiomyopathy } & Ischemic & 04 & 04 \\
\hline & Peripartum & 05 & 05 \\
\hline & Ethyl & 03 & 03 \\
\hline & Cardiothyreosis & 01 & 01 \\
\hline & Rhythmic & 01 & 01 \\
\hline & Primitive & 08 & 08 \\
\hline \multicolumn{2}{|c|}{ Hypertensive Cardiomyopathy } & 13 & 13 \\
\hline \multicolumn{2}{|r|}{ IPAH } & 01 & 01 \\
\hline \multicolumn{2}{|c|}{ Pericardial Disease } & 02 & 02 \\
\hline
\end{tabular}




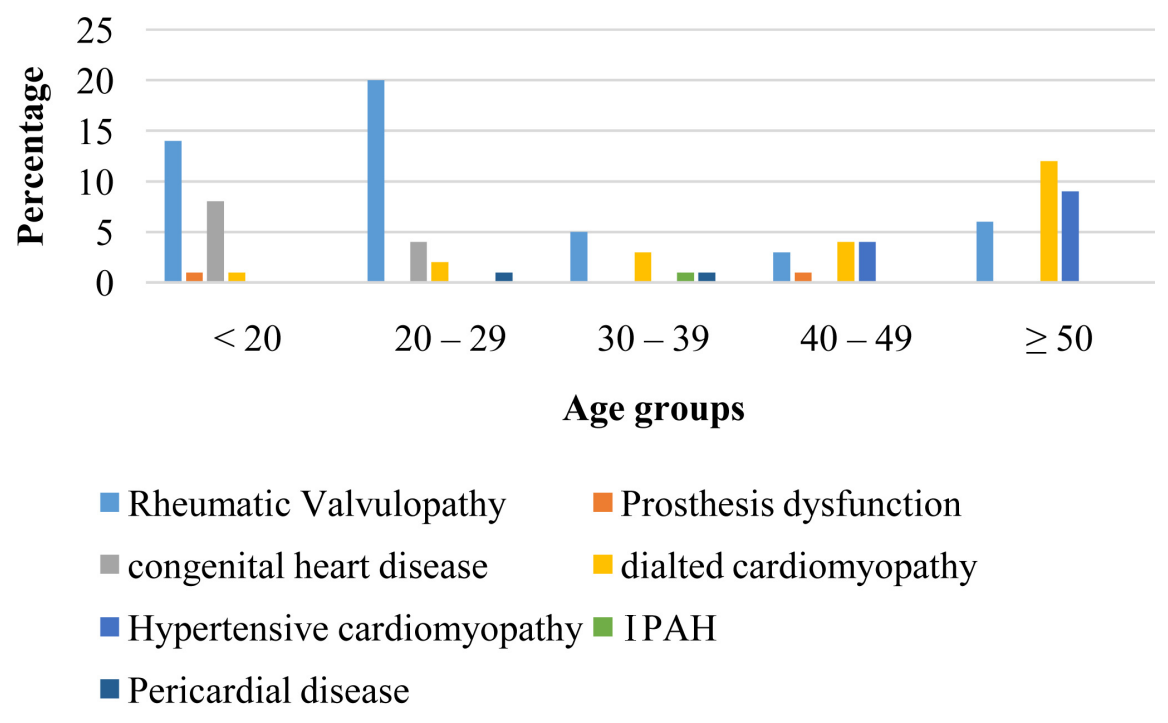

Figure 1. Distribution of etiologies according to age groups.

factors in our study were high blood pressure, obesity, diabetes, alcohol and renal dysfunction. The same risk factors have been found in most studies in both developed and Sub-Saharan Africa [16] [17]. Our patients often presented with a global CI chart (61\%) because of the delayed diagnosis related to difficulties in access to health care and the lack of specialists. This clinical presentation was noted by several authors in Sub-Saharan Africa [14] [18] [19]. The etiologies of $\mathrm{CI}$ in this study were dominated by non-ischemic causes. Rheumatic valvulopathy were the main causes (48\%), followed by DCM (22\%) and hypertensive cardiomyopathy (13\%). Ischemic cardiomyopathy was found only in $4 \%$ of cases. These results are consistent with most of the study series in Sub-Saharan Africa, where these 3 etiologies account for more than $65 \%$ of the causes of CI [13] [14] [19] [20] [21]. In the West, Ischemic heart disease is the most common etiology of CI. However, in Africa, Hypertensive cardiomyopathy is predominant [16] [22]. In a recent systematic review and meta-analysis of 22 African studies (1999-2017) 10098 patients; Hypertensive heart disease was the most common cause of CI (39.2\%), followed by Cardiomyopathy (21.4\%) and Rheumatic heart disease (14.1\%) [23]. Ischemic heart disease was rare (7.2\%) [23]. The size of our sample was not representative to assert the rarity of ischemic heart disease in Ndjamena, Chad. Further studies will be needed to provide an answer to this trend. However, according to age groups, our study revealed a clear predominance of Rheumatic heart disease and Congenital heart disease in children and young adults ( $<30$ years of age). The dilated cardiomyopathies and the hypertensive heart diseases mainly affected adults beyond 30 years of age.

\section{Limitations of Our Study}

The sample size of our study is not significant enough to reach formal conclusions. In this study, we did not include the therapeutic and evolutionary aspect 
of the patients which could have given us an idea about the overall care of the patients. Therefore, further studies are needed in the future with larger samples to better describe this pathology.

\section{Conclusion}

Cardiac Insufficiency is the main reason for hospitalization in the Cardiology Department at the Good Samaritan Hospital of N'Djamena in Chad. In this study, the four leading causes of CI were Rheumatic valvulopathy, congenital heart disease, dilated cardiomyopathy, and hypertensive cardiomyopathy. However, Ischemic heart disease was rare. In young people, the main etiology was rheumatic valvulopathy, whereas, in the elderly it was DCM.

\section{Conflicts of Interest}

The authors do not declare any conflict of interest.

\section{References}

[1] Ponikowski, P., Voors, A.A., Anker, S.D., et al. (2016) ESC Guidelines for the Diagnosis and Treatment of Acute and Chronic Heart Failure: The Task Force for the Diagnosis and Treatment of Acute and Chronic Heart Failure of the European Society of Cardiology (ESC). Developed with the Special Contribution of the Heart Failure Association (HFA) of the ESC. European Heart Journal, 18, 891-975.

https://doi.org/10.1093/eurheartj/ehw128

[2] Vos, T., Allen, C., Arora, M., et al. (2016) Global, Regional, and National Incidence, Prevalence, and Years Lived with Disability for 310 Diseases and Injuries, 1990-2015: A Systematic Analysis for the Global Burden of Disease Study 2015. The Lancet, 388, 1545-1602. https://doi.org/10.1016/S0140-6736(16)31678-6

[3] Roger, V.L. (2013) Epidemiology of Heart Failure. Circulation Research, 113, 646-659. https://doi.org/10.1161/CIRCRESAHA.113.300268

[4] Mosterd, A. and Hoes, A.W. (2007) Clinical Epidemiology of Heart Failure. Heart, 93, 1137-1146. https://doi.org/10.1136/hrt.2003.025270

[5] Ohlmeier, C., Mikolajczyk, R., Frick, J., Prütz, F., Haverkamp, W. and Garbe, E. (2015) Incidence, Prevalence and 1-Year All-Cause Mortality of Heart Failure in Germany: A Study Based on Electronic Healthcare Data of More than Six Million Persons. Clinical Research in Cardiology, 104, 688-696. https://doi.org/10.1007/s00392-015-0841-4

[6] Bui, A.L., Horwich, T.B. and Fonarow, G.C. (2011) Epidemiology and Risk Profile of Heart Failure. Nature Reviews Cardiology, 8, 30-41. https://doi.org/10.1038/nrcardio.2010.165

[7] Mayosi, B.M. (2007) Contemporary Trends in the Epidemiology and Management of Cardiomyopathy and Pericarditis in Sub-Saharan Africa. Heart, 93, 1176-1183. https://doi.org/10.1136/hrt.2007.127746

[8] WHO (2016) Global Health Estimates 2015: Death by Cause, Age, Sex, Country and Region, 2000-2015. World Health Organization, Geneva.

[9] Dunlay, S.M. and Roger, V.L. (2014) Understanding the Epidemic of Heart Failure: Past, Present, and Future. Current Heart Failure Reports, 11, 404-415. https://doi.org/10.1007/s11897-014-0220-x 
[10] Barasa, A., Schaufelberger, M., Lappas, G., Swedberg, K., Dellborg, M. and Rosengren, A. (2014) Heart Failure in Young Adults: 20-Year Trends in Hospitalization, Aetiology, and Case Fatality in Sweden. European Heart Journal, 35, 25-32. https://doi.org/10.1093/eurheartj/eht278

[11] Stewart, S., Ekman, I., Ekman, T., Odén, A. and Rosengren, A. (2010) Population Impact of Heart Failure and the Most Common Forms of Cancer: A Study of 1162 309 Hospital Cases in Sweden (1988 to 2004). Circulation: Cardiovascular Quality and Outcomes, 3, 573-580. https://doi.org/10.1161/CIRCOUTCOMES.110.957571

[12] Fofana, M., Toure, S., Dadhi, B.M., Sow, T., Yassima, C.A. and Damby, B.O. (1988) Considérations Étiologiques Et Nosologiques à propos de 574 cas de décompensationcardiaque à Conakry. Annales de Cardiologie et d'Angéiologie, 37, 419-424.

[13] Thiam, M. (2003) Insuffisancecardiaque en milieu cardiologiqueafricain. Bulletin de la Société de Pathologie Exotique, 96, 217-218.

[14] Kingue, S., Dzudie, A., Menanga, A., Akono, M., Ouankou, M. and Muna, W. (2005) A New Look of the Adult Chronic Heart Failure in Africa in the Age of the Doppler Echocardiography: Experience of the Medicine Department at Yaoundé General Hospital. Annales de Cardiologie et d’ Angéiologie (Paris), 54, 276-283. https://doi.org/10.1016/j.ancard.2005.04.014

[15] Pousset, F., Isnard, R. and Komajda, M. (2003) Insuffisance Cardiaque: Aspects épidémiologiques, cliniques et pronostiques. Encycl Méd Chir (Editions Scientifiqueset Médicales Elsevier SAS, Paris, tousdroitsréservés), Cardiologie, 11-036-G-20, $17 \mathrm{p}$.

[16] Beguin, M., Houpe, D., Peltier, M., Chalpelain, K., Lesbre, J.P. and Tribouilloy, C. (2004) Epidemiology and Aetiology of Cardiac Failure in the Somme. Archives des Maladies du Couret des Vaisseaux, 97, 113-119.

[17] Dzudie, A., Kengne, A.P., Mbahe, S., Menanga, A., Kenfack, M. and Kingue, S. (2008) Chronic Heart Failure, Select Risk Factors and Co-Morbidity among Adults Treated for Hypertension in Cardiac Referral Hospital in Cameroon. European Journal of Heart Failure, 10, 367-372. https://doi.org/10.1016/j.ejheart.2008.02.009

[18] Bertrand, E., Muna, W.F., Diouf, S.M., et al. (2006) Urgences Cardiovasculaires en Afrique Subsaharienne. Archives des Maladies du Cour et des Vaisseaux, 99, 1159-1165.

[19] Paule, P., Braem, L., Mioulet, D., Gil, J.M., Theron, A., Heno, P., et al. (2007) Insuffisance Cardiaque origine non infectieuse en zone tropicale: Approche écologique et principesthérapeutiques. Revue générale. Médicine Tropicale, 67, 579-586.

[20] Kwan, G.F., Bukhman, A.K., Miller, A.C., Ngoga, G., Mucumbitsi, J., Bavuma, C., et al. (2013) A Simplified Echocardiographic Strategy for Heart Failure Diagnosis and Management within an Integrated Non Communicable Disease Clinic at District Hospital Level for Sub-Saharan Africa. JACC: Heart Failure, 1, 230-236.

https://doi.org/10.1016/j.jchf.2013.03.006

[21] Tantchou Tchoumi, J.C., Ambassa, J.C., Kingue, S., Giamberti, A., Cirri, S., Frigiola, A., et al. (2011) Occurrence, Aetiology and Challenges in the Management of Congestive Heart Failure in Sub-Saharan Africa: Experience of the Cardiac Centre in Shisong, Cameroon. Pan African Medical Journal, 8, 11.

https://doi.org/10.4314/pamj.v8i1.71059

[22] Callender, T., Woodward, M., Roth, G., Farzadfar, F., Lemarie, J.C., Gicquel, S., et al. (2014) Heart Failure Care in Low and Middle Income Countries: A Systematic Review and Meta-Analysis. PLOS Medicine, 11, e1001699. https://doi.org/10.1371/journal.pmed.1001699 
[23] Agbor, V.N., Essouma, M., Ntusi, N.A.B., Nyaga, U.F., Bigna, J.J. and Noubiap, J.J. (2018) Heart Failure in Sub-Saharan Africa: A Contemporaneous Systematic Review and Meta-Analysis. International Journal of Cardiology, 257, 207-215. https://doi.org/10.1016/j.ijcard.2017.12.048

\section{Abbreviation}

CI: Cardiac Insufficiency; DCM: Dilated Cardiomyopathie; IPAH: Idiopathic Pulmonary Arterial Hypertension. 